\title{
Analyzing Area spectral efficiency and its impacts on the total spectrum requirements for IMT- Advanced
}

\author{
Amit Chaturvedi ${ }^{1}$ and Prof. Anil Solanki ${ }^{2}$ \\ ${ }^{1}$ Assistant Professor,. MCA Deptt, Govt. Engineering College, Ajmer \\ amit0581@gmail.com \\ ${ }^{2}$ Director, Meerut Institute of Engg. \& Tech., Meerut \\ directormiet09@gmail.com
}

\begin{abstract}
Terrestrial mobile systems generally employ a cellular architecture. Typical environments include macro, micro, and pico cells, further as a complementary hot spot. In order to establish high traffic capacity in IMT-2000 and its enhancement and systems beyond IMT-2000 with minimum handovers for mobile stations at various speeds and environments, in addition to maximizing spectral efficiency, it may be beneficial for the cells of IMT-2000 and its enhancement and systems beyond IMT-2000 to have different cell types related to mobile station parameters, such as mobility characteristics, output power, and types of services utilized. The area spectral efficiency is used in the spectrum requirement calculations to convert the capacity requirements in terms of bit/s/cell to the spectrum requirements in Hz. The area spectral efficiency factor should be measured below the IP layer and/or above L2. The spectral efficiency includes all RAT specific overheads, retransmission load, scheduling, etc. Even though for several teledensities the spectral efficiency might be the same, it is possible that the spectral efficiency will also vary between teledensities. This paper provides the results as spectrum required for the possible values of area spectrum efficiency in various time shifts.
\end{abstract}

\section{Keywords}

RAT, IMT, IP, LEO, GEO

\section{Introduction}

Fourth generation wireless communication faces the challenges of rapidly increasing mobile user demand against limited radio bandwidth. Splitting cells into smaller cells can reduce the frequency reuse distance to improve network capacity within a certain area. Other than increasing the cost of the fixed infrastructure, cell splitting also causes the problem of increasing handoff rate and even the handoff failure rate with high speed user roam in the network.

A cellular network covering an area is divided into a number of cells with a base station in each cell; a wired network (the fixed infrastructure) connects all these base stations. A mobile user will use a radio channel to connect to its closest base station. Through the mobile switching center (MSC) of the cellular network, this mobile user can get connected to a wired user or another mobile user. According to the cell size and service coverage area, four kinds of cells are used in cellular networks: Macro cell, Micro cell, Pico cell and Hot Spot. 
Figure 1 : A typical hierarchical cellular network

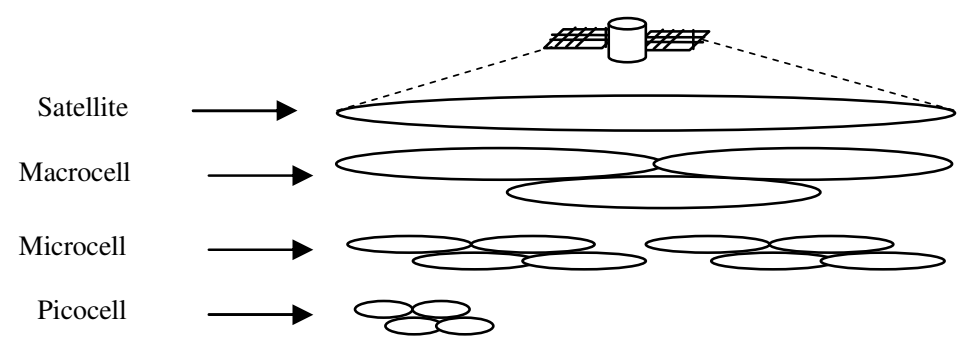

A satellite network covers a much larger area. It is well known that a system with three satellites in GEO can send or receive radio signals over almost all inhabited portion of the globe. Thus, seamless global mobile communications can be achieved with few handoffs. A satellite system employing Low Earth Orbit (LEO) reduces the transmission delay. In a LEO system, since the speed of a satellite is much higher than that of any mobile users on the ground, mobile users are relatively motionless. Each satellite passes a given user in a few minutes, so a handoff for a ground user from one satellite to another is required. On the known fixed orbit of satellites, handoff is easy to control. A satellite system is suitable for users with varying mobile speed, and can provide high speed data service.

Terrestrial mobile systems generally employ a cellular architecture. Typical environments include macro, micro, and Pico cells, further as a complementary hot spot. In order to establish high traffic capacity in IMT-2000 and its enhancement and systems beyond IMT-2000 with minimum handovers for mobile stations at various speeds and environments, in addition to maximizing spectral efficiency, it may be beneficial for the cells of IMT-2000 and its enhancement and systems beyond IMT-2000 to have different cell types related to mobile station parameters, such as mobility characteristics, output power, and types of services utilized. A cell layer would contain cells of the same type in a service area of IMT-2000 and its enhancement and systems beyond IMT-2000. In principle, it is possible to operate these different cell types simultaneously in the same geographical area. For example, a hot spot may complementarily be deployed in the dense urban area. All cells in the cell layer are fully or partly sharing the same spectrum resource.

\subsection{Macro cell}

The macro cells are with a large cell radius, dependent on the teledensity or service environment. This cell radius is typically more than $1 \mathrm{~km}$ in urban to more than $40 \mathrm{~km}$ in rural. The typical environment would include an outdoor flat terrain or rural area with lower height and density of buildings or obstacles. In the macro cell environment, high mobility needs to be supported since usage scenarios in outdoor environments would mainly be considered. It should be noted, however, usage scenarios inside a building with low mobility may also be considered. In the macro cell environment services may require large coverage area.

In case of cellular environment, several numbers of channels are required for deployment. Guard bands have to be accommodated to reduce interference between adjacent bands. 


\subsection{Micro cell}

The micro cells are with a cell radius, typically from $50 \mathrm{~m}$ to $1 \mathrm{~km}$. The typical environment would include an outdoor suburban or urban area with relatively higher height and high density of buildings. In the micro cell environment, mobility from low to high should be supported since usage scenario in both outdoor and indoor would be considered.

In case of cellular environment, several numbers of channels is required for deployment. Guard bands have to be accommodated to reduce interference between adjacent bands.

\subsection{Pico cell}

The Pico cells are with a small cell radius, typically less than $50 \mathrm{~m}$. The typical environment would include an outdoor street in dense urban areas with high density of buildings. Deployment in an underground complex area may also be considered. In the Pico cell environment, low mobility should mainly be supported since usage scenarios in outdoor in a city or indoor would be considered. It should be noted, however, relatively high mobility should be considered if a main street is included in the coverage area.

In case of cellular environment, several numbers of channels is required for deployment. Guard bands have to be accommodated to reduce interference between adjacent bands.

\subsection{Hotspot}

A hotspot is a centre (limited geographic area) of high levels of activity and/or user density using potentially high data rates, within a larger geographic area of lower activity/density generally encompassing lower data rate usage. Hotspots are a geographic area supported by one or more cells of a small radius, typically less than several tens of meters. There may be no similar radio coverage in geographic areas between hotspots.

The typical environment would include indoor and semi-outdoor in dense urban area with high density of buildings or objects. The hotspot may be deployed in an airport, a station, or, an underground complex area. In the hotspot environment, low mobility should mainly be supported since usage scenario in semi-outdoor in a city or indoor would be considered.

In case of hotspot environment, the number of required channels may be smaller than that in a cellular environment since the interference from surrounding cells may less. The hotspot is in response to the requirement for very high data rates (up to $1 \mathrm{Gbit} / \mathrm{s}$ ) in quasi-static or pedestrian speed. High traffic requirements characterized by dense urban service environments are mainly expected.

Maximum cell area per radio environment $\mathrm{km} 2 *$

\begin{tabular}{|c|c|c|c|}
\hline \multirow{2}{*}{ Radio environment } & \multicolumn{3}{|c|}{ Teledensity } \\
\cline { 2 - 4 } & Dense urban & Suburban & Rural \\
\hline Macro cell & 0.65 & 1.5 & 8.0 \\
\hline Micro cell & 0.1 & 0.1 & 0.1 \\
\hline Pico cell & $1.6 \times 10^{-3}$ & $1.6 \times 10^{-3}$ & $1.6 \times 10^{-3}$ \\
\hline Hot Spot & $6.5 \times 10^{-5}$ & $6.5 \times 10^{-5}$ & $6.5 \times 10^{-5}$ \\
\hline
\end{tabular}


* Cell size is heavily influenced by frequency of operation. The maximum cell sizes designated in the table are derived from assumption that a significant amount of spectrum likely to be required can only be satisfied using frequencies towards the $6 \mathrm{GHz}$ area. Other approaches that could lead to higher maximum cell sizes, e.g. the scenario at large area with low teledensity coverage, have not been considered.

\section{Why a hierarchical cellular system?}

Demand from wireless users is growing rapidly. Besides voice and data services as in 3G, 4G is expected to provide fully IP-bases services with higher data rates up to $1 \mathrm{Gbps}$ for nomadic / low mobility users and $100 \mathrm{Mbps}$ for high mobility users. Since the existing bandwidth reserved for wireless networks is limited, methods to improve radio spectrum efficiency are needed so that higher network capacity can be achieved.

Cell splitting can improve cellular network capacity because, by using smaller cells instead of larger ones, the frequency reuse distance is reduced. The same channel can be reused more times in a cellular network, and virtually more wireless channels can be provided by the network simultaneously; thus, system capacity increases. A cell of smaller size can also provide relatively wider coherence channel bandwidth because of its shorter channel delay spread, so a small cell is more suitable to support high speed services in a $4 \mathrm{G}$ wireless network.

However, a smaller cell size may cause a mobile user to cross more cells more often during its lifetime. There are more handoff operations for each user, and the system load increases. When a mobile user is too fast relative to the cell size, it may get into a new cell before its previous handoff processing finishes. Then the call has to be dropped, and the service cannot be completed.

To avoid the shortcomings of smaller sized cells mentioned above, a hierarchical cellular network is shown above in fig 1. The cellular network consists of different tiers. Each tier has different sizes of cells, and large cells are overlaid on small cells. Low-speed users are normally assigned to smaller cells, while high-speed users are originally assigned to large cells. System capacity increases while handoff load is limited.

In a hierarchical cellular network, mobile users with different mobility or service requirements are initially assigned to different tiers. Radio resources are assigned to different tiers. To reduce complexity of operation, such as the complexity of dynamic frequency reuse control in a tiered network, the radio resource is normally assigned to the different tiers in a fixed manner. Because of varying traffic, it may e that when a user gets into a cell, there is not free channel in this cell, but there may be free channels in the cells of its upper or lower tiers. To optimize network spectrum efficiency, in a hierarchical network a user may go up or down to use free channels in other tiers. Generally, this procedure is called overflow. Since better traffic balance is achieved among tiers if mobile users stay in their original tier, a mobile user who has overflowed to a "alien" tier should go back to its original tier if a channel is released in its original tire. This procedure is called take-back.

In a macrocell / microcell network's performance is examined. Low-speed users are originally assigned to microcells and high-speed users to macro cells. Overflow and take-back are used to improve spectrum efficiency. 
Figure 2: A macro cell and portable microcells.

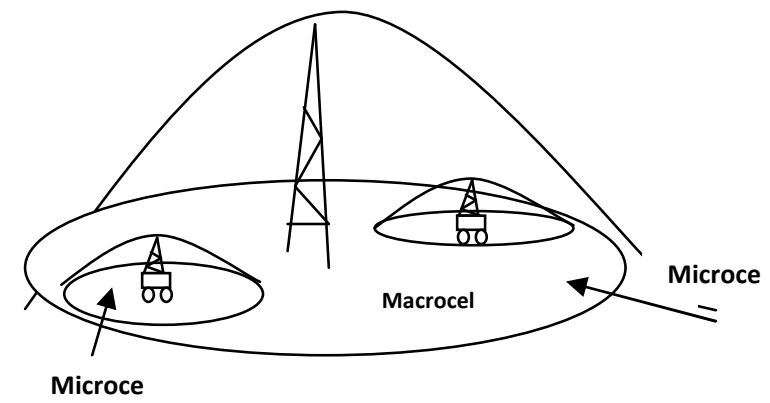

\section{Area Spectral efficiency}

The area spectral efficiency is used in the spectrum requirement calculations to convert the capacity requirements in terms of bit/s/cell to the spectrum requirements in $\mathrm{Hz}$. The area spectral efficiency factor should be measured below the IP layer and/or above L2. The spectral efficiency includes all RAT specific overheads, retransmission load, scheduling, etc. Even though for several teledensities the spectral efficiency might be the same, it is possible that the spectral efficiency will also vary between teledensities.

The spectral efficiency values for RAT Group 1 are shown in Table 22. They are bases on figures that have been proposed for the long term evolution of IMT-2000 technologies. The spectral efficiency values for RAT Group 2 are assumed to be dependent on the forecast year. The values for RAT Group 2 in 2010, 2015, and 2020 are shown in Table 23a to 23e, respectively.

Table 22a

Area spectral efficiency RAT Group 12010 (bit/s/Hz)

Unicast area spectral efficiency

(bit/s/Hz/cell)

\begin{tabular}{|l|l|l|l|l|}
\hline \multirow{2}{*}{$\begin{array}{l}\text { Telede } \\
\text { nsity }\end{array}$} & \multicolumn{4}{|l|}{ Radio environments } \\
\cline { 2 - 5 } & $\begin{array}{l}\text { Macro } \\
\text { cell }\end{array}$ & $\begin{array}{l}\text { Micro } \\
\text { cell }\end{array}$ & $\begin{array}{l}\text { Pico } \\
\text { cell }\end{array}$ & $\begin{array}{l}\text { Hot } \\
\text { spot }\end{array}$ \\
\hline $\begin{array}{l}\text { Dense } \\
\text { urban }\end{array}$ & 1 & 2 & 2 & - \\
\hline $\begin{array}{l}\text { Subur } \\
\text { ban }\end{array}$ & 1 & 2 & 2 & - \\
\hline Rural & 1 & 2 & 2 & - \\
\hline
\end{tabular}

Multicast area spectral efficiency (bit/s/Hz/cell)

\begin{tabular}{|l|l|l|l|l|}
\hline \multirow{2}{*}{$\begin{array}{l}\text { Telede } \\
\text { nsity }\end{array}$} & \multicolumn{4}{|l|}{ Radio environments } \\
\cline { 2 - 5 } & $\begin{array}{l}\text { Macr } \\
\text { o cell }\end{array}$ & $\begin{array}{l}\text { Micr } \\
\text { o cell }\end{array}$ & $\begin{array}{l}\text { Pico } \\
\text { cell }\end{array}$ & $\begin{array}{l}\text { Hot } \\
\text { spot }\end{array}$ \\
\hline $\begin{array}{l}\text { Dense } \\
\text { urban }\end{array}$ & 0.5 & 1 & 1 & - \\
\hline $\begin{array}{l}\text { Suburb } \\
\text { an }\end{array}$ & 0.5 & 1 & 1 & - \\
\hline Rural & 0.5 & 1 & 1 & - \\
\hline
\end{tabular}


International Journal of Distributed and Parallel Systems (IJDPS) Vol.3, No.2, March 2012

Table $22 b$

Area spectral efficiency RAT Group 12015 (bit/s/Hz)

Unicast area spectral efficiency (bit/s/Hz/cell)

\begin{tabular}{|l|l|l|l|l|}
\hline \multirow{2}{*}{$\begin{array}{l}\text { Teledensi } \\
\text { ty }\end{array}$} & \multicolumn{4}{|l|}{ Radio environments } \\
\cline { 2 - 5 } & $\begin{array}{l}\text { Macr } \\
\text { o cell }\end{array}$ & $\begin{array}{l}\text { Micr } \\
\text { o cell }\end{array}$ & $\begin{array}{l}\text { Pico } \\
\text { cell }\end{array}$ & $\begin{array}{l}\text { Hot } \\
\text { spot }\end{array}$ \\
\hline $\begin{array}{l}\text { Dense } \\
\text { urban }\end{array}$ & 1.5 & 3 & 3 & - \\
\hline Suburban & 1.5 & 3 & 3 & - \\
\hline Rural & 1.5 & 3 & 3 & - \\
\hline
\end{tabular}

Multicast area spectral efficiency (bit/s/Hz/cell)

\begin{tabular}{|l|l|l|l|l|}
\hline \multirow{2}{*}{$\begin{array}{l}\text { Teledensit } \\
\text { y }\end{array}$} & \multicolumn{4}{|l|}{ Radio environments } \\
\cline { 2 - 5 } & $\begin{array}{l}\text { Macro } \\
\text { cell }\end{array}$ & $\begin{array}{l}\text { Micr } \\
\text { o cell }\end{array}$ & $\begin{array}{l}\text { Pico } \\
\text { cell }\end{array}$ & $\begin{array}{l}\text { Hot } \\
\text { spot }\end{array}$ \\
\hline $\begin{array}{l}\text { Dense } \\
\text { urban }\end{array}$ & 0.75 & 1.5 & 1.5 & - \\
\hline Suburban & 0.75 & 1.5 & 1.5 & - \\
\hline Rural & 0.75 & 1.5 & 1.5 & - \\
\hline
\end{tabular}

Table 22c

Area spectral efficiency RAT Group 12020 (bit/s/Hz)

Unicast area spectral efficiency

(bit/s/Hz/cell)

\begin{tabular}{|l|l|l|l|l|}
\hline \multirow{2}{*}{$\begin{array}{l}\text { Teledensit } \\
\text { y }\end{array}$} & \multicolumn{4}{|l|}{ Radio environments } \\
\cline { 2 - 5 } & $\begin{array}{l}\text { Macro } \\
\text { cell }\end{array}$ & $\begin{array}{l}\text { Micr } \\
\text { o cell }\end{array}$ & $\begin{array}{l}\text { Pico } \\
\text { cell }\end{array}$ & $\begin{array}{l}\text { Hot } \\
\text { spot }\end{array}$ \\
\hline $\begin{array}{l}\text { Dense } \\
\text { urban }\end{array}$ & 2 & 4 & 4 & - \\
\hline Suburban & 2 & 4 & 4 & - \\
\hline Rural & 2 & 4 & 4 & - \\
\hline
\end{tabular}

Multicast area spectral efficiency (bit/s/Hz/cell)

\begin{tabular}{|l|l|l|l|l|}
\hline \multirow{2}{*}{$\begin{array}{l}\text { Teledensit } \\
\text { y }\end{array}$} & \multicolumn{4}{|l|}{ Radio environments } \\
\cline { 2 - 5 } & $\begin{array}{l}\text { Macro } \\
\text { cell }\end{array}$ & $\begin{array}{l}\text { Micr } \\
\text { o cell }\end{array}$ & $\begin{array}{l}\text { Pico } \\
\text { cell }\end{array}$ & $\begin{array}{l}\text { Hot } \\
\text { spot }\end{array}$ \\
\hline $\begin{array}{l}\text { Dense } \\
\text { urban }\end{array}$ & 1 & 2 & 2 & - \\
\hline Suburban & 1 & 2 & 2 & - \\
\hline Rural & 1 & 2 & 2 & - \\
\hline
\end{tabular}

Table 23a is based on simulation results of wireless technologies and expected to be implemented in 2012. Table 23e is derived from theoretical limits allowing an estimated margin for implementation. Tables $23 \mathrm{~b}$ to $23 \mathrm{~d}$ represent possible evolution paths within the values shown in Tables 23a and 23e.

Table 23a

Area spectral efficiency RAT Group 22010 (bit/s/Hz)

Unicast area spectral efficiency

(bit/s/Hz/cell)

\begin{tabular}{|l|l|l|l|l|}
\hline \multirow{2}{*}{$\begin{array}{l}\text { Teledens } \\
\text { ity }\end{array}$} & \multicolumn{4}{|l|}{ Radio environments } \\
\cline { 2 - 5 } & $\begin{array}{l}\text { Macr } \\
\text { o cell }\end{array}$ & $\begin{array}{l}\text { Micr } \\
\text { o } \\
\text { cell }\end{array}$ & $\begin{array}{l}\text { Pico } \\
\text { cell }\end{array}$ & $\begin{array}{l}\text { Hot } \\
\text { spot }\end{array}$ \\
\hline $\begin{array}{l}\text { Dense } \\
\text { urban }\end{array}$ & 2 & 2.5 & 3 & 5 \\
\hline $\begin{array}{l}\text { Suburba } \\
\text { n }\end{array}$ & 2 & 2.5 & 3 & 5 \\
\hline Rural & 2 & 2.5 & 3 & 5 \\
\hline
\end{tabular}

Multicast area spectral efficiency (bit/s/Hz/cell)

\begin{tabular}{|l|l|l|l|l|}
\hline Teledensity & \multicolumn{4}{|c|}{ Radio environments } \\
\cline { 2 - 6 } & $\begin{array}{l}\text { Mac } \\
\text { ro } \\
\text { cell }\end{array}$ & $\begin{array}{l}\text { Mi } \\
\text { cro } \\
\text { cell }\end{array}$ & $\begin{array}{l}\text { Pic } \\
\text { o } \\
\text { cell }\end{array}$ & $\begin{array}{l}\text { Ho } \\
\text { sp } \\
\text { ot }\end{array}$ \\
\hline Dense urban & 1 & $\begin{array}{l}1.2 \\
5\end{array}$ & 1.5 & 2.5 \\
\hline Suburban & 1 & $\begin{array}{l}1.2 \\
5\end{array}$ & 1.5 & 2.5 \\
\hline Rural & 1 & $\begin{array}{l}1.2 \\
5\end{array}$ & 1.5 & 2.5 \\
\hline
\end{tabular}


International Journal of Distributed and Parallel Systems (IJDPS) Vol.3, No.2, March 2012

Table $23 b$

Area spectral efficiency RAT Group 2015 (bit/s/Hz) (Set 1)

Unicast area spectral efficiency

(bit/s/Hz/cell)

\begin{tabular}{|l|l|l|l|l|}
\hline \multirow{2}{*}{$\begin{array}{l}\text { Teledensi } \\
\text { ty }\end{array}$} & \multicolumn{4}{|l|}{ Radio environments } \\
\cline { 2 - 5 } & $\begin{array}{l}\text { Macro } \\
\text { cell }\end{array}$ & $\begin{array}{l}\text { Micr } \\
\text { o cell }\end{array}$ & $\begin{array}{l}\text { Pico } \\
\text { cell }\end{array}$ & $\begin{array}{l}\text { Hot } \\
\text { spot }\end{array}$ \\
\hline $\begin{array}{l}\text { Dense } \\
\text { urban }\end{array}$ & 4 & 5 & 6 & 7 \\
\hline Suburban & 4 & 5 & 6 & 7 \\
\hline Rural & 4 & 5 & 6 & 7 \\
\hline
\end{tabular}

Multicast area spectral efficiency (bit/s/Hz/cell)

\begin{tabular}{|l|l|l|l|l|}
\hline \multirow{2}{*}{$\begin{array}{l}\text { Teledensi } \\
\text { ty }\end{array}$} & \multicolumn{4}{|l|}{ Radio environments } \\
\cline { 2 - 5 } & $\begin{array}{l}\text { Macro } \\
\text { cell }\end{array}$ & $\begin{array}{l}\text { Micr } \\
\text { o cell }\end{array}$ & $\begin{array}{l}\text { Pico } \\
\text { cell }\end{array}$ & $\begin{array}{l}\text { Hot } \\
\text { spot }\end{array}$ \\
\hline $\begin{array}{l}\text { Dense } \\
\text { urban }\end{array}$ & 2 & 2.5 & 3 & 3.5 \\
\hline Suburban & 2 & 2.5 & 3 & 3.5 \\
\hline Rural & 2 & 2.5 & 3 & 3.5 \\
\hline
\end{tabular}

Table 23c

Area spectral efficiency RAT Group 2015 (bit/s/Hz) (Set 2)

Unicast area spectral efficiency (bit/s/Hz/cell)

\begin{tabular}{|l|l|l|l|l|}
\hline \multirow{2}{*}{$\begin{array}{l}\text { Teledensit } \\
\text { y }\end{array}$} & \multicolumn{4}{|l|}{ Radio environments } \\
\cline { 2 - 5 } & $\begin{array}{l}\text { Macro } \\
\text { cell }\end{array}$ & $\begin{array}{l}\text { Micr } \\
\text { o cell }\end{array}$ & $\begin{array}{l}\text { Pico } \\
\text { cell }\end{array}$ & $\begin{array}{l}\text { Hot } \\
\text { spot }\end{array}$ \\
\hline $\begin{array}{l}\text { Dense } \\
\text { urban }\end{array}$ & 4.5 & 5.5 & 7 & 8 \\
\hline Suburban & 4.5 & 5.5 & 7 & 8 \\
\hline Rural & 4.5 & 5.5 & 7 & 8 \\
\hline
\end{tabular}

Multicast area spectral efficiency (bit/s/Hz/cell)

\begin{tabular}{|l|l|l|l|l|}
\hline \multirow{2}{*}{$\begin{array}{l}\text { Teledensit } \\
\text { y }\end{array}$} & \multicolumn{4}{|l|}{ Radio environments } \\
\cline { 2 - 5 } & $\begin{array}{l}\text { Macro } \\
\text { cell }\end{array}$ & $\begin{array}{l}\text { Micr } \\
\text { o cell }\end{array}$ & $\begin{array}{l}\text { Pico } \\
\text { cell }\end{array}$ & $\begin{array}{l}\text { Hot } \\
\text { spot }\end{array}$ \\
\hline $\begin{array}{l}\text { Dense } \\
\text { urban }\end{array}$ & 2.25 & 2.75 & 3.5 & 4 \\
\hline Suburban & 2.25 & 2.75 & 3.5 & 4 \\
\hline Rural & 2.25 & 2.75 & 3.5 & 4 \\
\hline
\end{tabular}

Table 23d

Area spectral efficiency RAT Group 22015 (bit/s/Hz) (Set 3) Unicast area spectral efficiency (bit/s/Hz/cell)

\begin{tabular}{|l|l|l|l|l|}
\hline \multirow{2}{*}{$\begin{array}{l}\text { Teledens } \\
\text { ity }\end{array}$} & \multicolumn{4}{|l|}{ Radio environments } \\
\cline { 2 - 5 } & $\begin{array}{l}\text { Macr } \\
\text { o cell }\end{array}$ & $\begin{array}{l}\text { Micr } \\
\text { o } \\
\text { cell }\end{array}$ & $\begin{array}{l}\text { Pico } \\
\text { cell }\end{array}$ & $\begin{array}{l}\text { Hot } \\
\text { spot }\end{array}$ \\
\hline $\begin{array}{l}\text { Dense } \\
\text { urban }\end{array}$ & 5 & 6 & 8 & 9 \\
\hline Suburban & 5 & 6 & 8 & 9 \\
\hline Rural & 5 & 6 & 8 & 9 \\
\hline
\end{tabular}

Multicast area spectral efficiency (bit/s/Hz/cell)

\begin{tabular}{|l|l|l|l|l|}
\hline \multirow{2}{*}{ Teledensity } & \multicolumn{4}{|l|}{ Radio environments } \\
\cline { 2 - 5 } & $\begin{array}{l}\text { Macro } \\
\text { cell }\end{array}$ & $\begin{array}{l}\text { Micro } \\
\text { cell }\end{array}$ & $\begin{array}{l}\text { Pico } \\
\text { cell }\end{array}$ & $\begin{array}{l}\text { Hot } \\
\text { spot }\end{array}$ \\
\hline $\begin{array}{l}\text { Dense } \\
\text { urban }\end{array}$ & 2.5 & 3 & 4 & 4.5 \\
\hline Suburban & 2.5 & 3 & 4 & 4.5 \\
\hline Rural & 2.5 & 3 & 4 & 4.5 \\
\hline
\end{tabular}


International Journal of Distributed and Parallel Systems (IJDPS) Vol.3, No.2, March 2012

Table 23e

Area spectral efficiency RAT Group 2020 (bit/s/Hz) (Set 1)

Unicast area spectral efficiency

(bit/s/Hz/cell)

\begin{tabular}{|l|l|l|l|l|}
\hline \multirow{2}{*}{$\begin{array}{l}\text { Teledensit } \\
\text { y }\end{array}$} & \multicolumn{4}{|l|}{ Radio environments } \\
\cline { 2 - 5 } & $\begin{array}{l}\text { Macro } \\
\text { cell }\end{array}$ & $\begin{array}{l}\text { Micr } \\
\text { o cell }\end{array}$ & $\begin{array}{l}\text { Pico } \\
\text { cell }\end{array}$ & $\begin{array}{l}\text { Hot } \\
\text { spot }\end{array}$ \\
\hline $\begin{array}{l}\text { Dense } \\
\text { urban }\end{array}$ & 5 & 6 & 8 & 9 \\
\hline Suburban & 5 & 6 & 8 & 9 \\
\hline Rural & 5 & 6 & 8 & 9 \\
\hline
\end{tabular}

Multicast area spectral efficiency

(bit/s/Hz/cell)

\begin{tabular}{|l|l|l|l|l|}
\hline \multirow{2}{*}{$\begin{array}{l}\text { Teledensi } \\
\text { ty }\end{array}$} & \multicolumn{4}{|l|}{ Radio environments } \\
\cline { 2 - 5 } & $\begin{array}{l}\text { Macr } \\
\text { o cell }\end{array}$ & $\begin{array}{l}\text { Micr } \\
\text { o cell }\end{array}$ & $\begin{array}{l}\text { Pico } \\
\text { cell }\end{array}$ & $\begin{array}{l}\text { Hot } \\
\text { spot }\end{array}$ \\
\hline $\begin{array}{l}\text { Dense } \\
\text { urban }\end{array}$ & 2.5 & 3 & 4 & 4.5 \\
\hline Suburban & 2.5 & 3 & 4 & 4.5 \\
\hline Rural & 2.5 & 3 & 4 & 4.5 \\
\hline
\end{tabular}

Table 23f

Area spectral efficiency RAT Group 2020 (bit/s/Hz) (Set 2)

Unicast area spectral efficiency

(bit/s/Hz/cell)

\begin{tabular}{|l|l|l|l|l|}
\hline \multirow{2}{*}{$\begin{array}{l}\text { Teledensit } \\
\text { y }\end{array}$} & \multicolumn{4}{|l|}{ Radio environments } \\
\cline { 2 - 5 } & $\begin{array}{l}\text { Macro } \\
\text { cell }\end{array}$ & $\begin{array}{l}\text { Micr } \\
\text { o cell }\end{array}$ & $\begin{array}{l}\text { Pico } \\
\text { cell }\end{array}$ & $\begin{array}{l}\text { Hot } \\
\text { spot }\end{array}$ \\
\hline $\begin{array}{l}\text { Dense } \\
\text { urban }\end{array}$ & 6 & 7 & 9 & 10 \\
\hline Suburban & 6 & 7 & 9 & 10 \\
\hline Rural & 6 & 7 & 9 & 10 \\
\hline
\end{tabular}

Multicast area spectral efficiency

(bit/s/Hz/cell)

\begin{tabular}{|l|l|l|l|l|}
\hline \multirow{2}{*}{\begin{tabular}{l} 
Teledensit \\
\cline { 2 - 5 }
\end{tabular}} & \multicolumn{4}{|l|}{ Radio environments } \\
\cline { 2 - 5 } & Macro & $\begin{array}{l}\text { Micr } \\
\text { o cell }\end{array}$ & $\begin{array}{l}\text { Pico } \\
\text { cell }\end{array}$ & $\begin{array}{l}\text { Hot } \\
\text { spot }\end{array}$ \\
\hline $\begin{array}{l}\text { Dense } \\
\text { urban }\end{array}$ & 3 & 3.5 & 4.5 & 5 \\
\hline Suburban & 3 & 3.5 & 4.5 & 5 \\
\hline Rural & 3 & 3.5 & 4.5 & 5 \\
\hline
\end{tabular}

Table 23g

Area spectral efficiency RAT Group 22020 (bit/s/Hz) (Set 3)

Unicast area spectral efficiency

(bit/s/Hz/cell)

\begin{tabular}{|l|l|l|l|l|}
\hline \multirow{2}{*}{$\begin{array}{l}\text { Teledensi } \\
\text { ty }\end{array}$} & \multicolumn{4}{|l|}{ Radio environments } \\
\cline { 2 - 5 } & $\begin{array}{l}\text { Macr } \\
\text { o cell }\end{array}$ & $\begin{array}{l}\text { Micr } \\
\text { o } \\
\text { cell }\end{array}$ & $\begin{array}{l}\text { Pico } \\
\text { cell }\end{array}$ & $\begin{array}{l}\text { Hot } \\
\text { spot }\end{array}$ \\
\hline $\begin{array}{l}\text { Dense } \\
\text { urban }\end{array}$ & 6 & 7 & 10 & 10 \\
\hline Suburban & 6 & 7 & 10 & 10 \\
\hline Rural & 6 & 7 & 10 & 10 \\
\hline
\end{tabular}

Multicast area spectral efficiency

(bit/s/Hz/cell)

\begin{tabular}{|l|l|l|l|l|}
\hline \multirow{2}{*}{$\begin{array}{l}\text { Teledensit } \\
\text { y }\end{array}$} & \multicolumn{4}{|l}{ Radio environments } \\
\cline { 2 - 5 } & $\begin{array}{l}\text { Macro } \\
\text { cell }\end{array}$ & $\begin{array}{l}\text { Micro } \\
\text { cell }\end{array}$ & $\begin{array}{l}\text { Pico } \\
\text { cell }\end{array}$ & $\begin{array}{l}\text { Hot } \\
\text { spot }\end{array}$ \\
\hline $\begin{array}{l}\text { Dense } \\
\text { urban }\end{array}$ & 3 & 3.5 & 5 & 5 \\
\hline Suburban & 3 & 3.5 & 5 & 5 \\
\hline Rural & 3 & 3.5 & 5 & 5 \\
\hline
\end{tabular}


Accurate estimation of spectral efficiency of a radio system is inherently difficult interference, scheduling, protocol efforts etc.; all come into play and interact in a complicated manner. Also the results are heavily dependent on a number of assumptions such as site density, the number of sector per site, the number of transmit and receive antennas, the complexity of the signal processing in the receiver etc.

\subsection{Macro cell}

Without advanced antenna systems, spectral efficiencies in the order of 1-2 bit/s/Hz/cell seem to be a reasonable baseline assumption. fourth generation technologies will be the integration of more advanced antenna systems, e.g. beam forming and MIMO. A conservation estimation of $2-3 \mathrm{bit} / \mathrm{s} / \mathrm{Hz} / \mathrm{cell}$ is proposed.

Hence we have assumed the spectral efficiency for macro cell up to 2-6 bit/s/Hz/cell.

\subsection{Micro, Pico cells, and hot spots}

The micro and Pico cell spectral efficiencies are estimated somewhat higher than for macro cell : 2-7 bit/s/Hz/cell for micro cell and 3-9 bit/s/Hz/cell for Pico cell. Better efficiency for smaller cells is also motivated by the facto that they will likely have users with lower mobility, and that coverage limitation is less likely an issue than for macro cell. This trend is continued for hot spot scenarios, where we additionally do not suffer from interference limitation. There for spectral efficiencies in the range of $5-10 \mathrm{bit} / \mathrm{s} / \mathrm{Hz} / \mathrm{cell}$ seem to be reasonable for hot spot scenarios.

Hence summarized details are as follows:

\begin{tabular}{|l|l|l|l|l|}
\cline { 2 - 5 } \multicolumn{1}{c|}{} & Macro cell & Micro cell & Pico cell & Hot spot \\
\hline $\begin{array}{l}\text { Area spectral efficiency } \\
\text { (bit/s/Hz/cell) }\end{array}$ & $2-6$ & $2-7$ & $3-9$ & $5-10$ \\
\hline
\end{tabular}

\subsection{Area spectral efficiency for multicasting}

For multicasting the spectral efficiency is generally lower, because the transmission benefits from multi user diversity to a smaller extent. The radio resource usage is determined by the user of a multicast group that has the worst reception conditions. Although in the cell of multi-cell multicasting, the multicast transmission frequently can benefit from soft combining of the signals received from adjacent transmitters, this does not fully compensate for the low multi user diversity. Therefore, a lower spectral efficiency is assumed for multicasting transmissions, on the order of $50 \%$ of the unicast case.

\section{Conclusion}

As area spectral efficiency is used in the spectrum requirement calculations to convert the capacity requirements in terms of bit/s/cell to the spectrum requirements in $\mathrm{Hz}$. We have 
measured the area spectral efficiency factor here in this paper. We take the above mention values mentioned in the table 22 for RAT Group 1 and take Table 23a, 23b and 23e for 2010, 2015 and 2020 for RAT Group 2. Then the spectrum requirement will be as follows:

\begin{tabular}{|c|r|r|r|}
\hline \multicolumn{4}{|c|}{ Spectrum requirement in $\mathbf{M H z}$} \\
\hline $\begin{array}{c}\text { Spectrum for } \\
\text { RAT Group \#1 }\end{array}$ & year 2010 & year 2015 & year 2020 \\
\hline RAT Group \#2 & 0 & 880 & 880 \\
\hline Total Spectrum & 840 & 540 & 820 \\
\hline
\end{tabular}

And if we consider the set 2 i.e. Table $23 \mathrm{c}$ and $23 \mathrm{f}$ for 2015 and 2020 for RAT Group2, then the spectrum requirement will as follows :

\begin{tabular}{|c|r|r|r|}
\hline \multicolumn{4}{|c|}{ Spectrum requirement in $\mathbf{M H z}$} \\
\hline $\begin{array}{c}\text { Spectrum for } \\
\text { RAT Group \#1 }\end{array}$ & year 2010 & year 2015 & year 2020 \\
\cline { 2 - 4 } RAT Group \#2 & 840 & 880 & 880 \\
\hline Total Spectrum & 0 & 420 & 720 \\
\hline
\end{tabular}

And if we consider the set3 i.e. Table $23 \mathrm{~d}$ and $23 \mathrm{~g}$ for 2015 and 2020 for RAT Group2, then the spectrum requirement will as follows :

\begin{tabular}{|c|r|r|r|}
\hline \multicolumn{4}{|c|}{ Spectrum requirement in MHz} \\
\hline $\begin{array}{c}\text { Spectrum for } \\
\text { RAT Group \#1 }\end{array}$ & year 2010 & year 2015 & year 2020 \\
\cline { 2 - 4 } RAT Group \#2 & 840 & 880 & 880 \\
\hline Total Spectrum & 0 & 420 & 720 \\
\hline
\end{tabular}

\section{ACKNOWLEDGEMENTS}

The authors like to give thanks to all the friends who directly or indirectly supports us to accomplish this work.

\section{References}

[1]. Rep. ITU-R M.2074 "Radio aspects for the terrestrial component of IMT-2000 and systems beyond IMT-2000”, 2005

[2]. Rep. ITU-R M.2078 "Estimated spectrum bandwidth requirements for the future development of IMT-2000 and IMT-Advanced", 2006

[3]. Rep. ITU-R M.2072 "World mobile telecommunication market forecast", 2005

[4]. Wu X, Mukharjee B, and Ghosal D, "Hierarchical Architectures in the ThirdGeneration cellular network", 2004 
International Journal of Distributed and Parallel Systems (IJDPS) Vol.3, No.2, March 2012

[5]. Kim Y, Kwon T, and Hong D, "Area Spectral Efficiency of shared spectrum Hierarchical cell Structure Networks", published in IEEE Transactions on vehicular technology, vol. 59, No. 8, Oct, 2010

[6]. Martin J, Amin R, Eltwil A, Hussien A, "Using Reconfigurable Devices to Maximize Spectral Efficiency in Future Heterogeneous Wireless System"

[7]. Maltsev A., Khoryeav A., Maslennikov R., Morozov G., "Analysis of IEEE 802.16m and 3GPP LTE Release 10 technologies by Russian Evaluation Group for IMT-Advanced", 2010 International congress on Ultra Modem Telecommunications and Control Systems and Workshops, 2010

[8]. Kumar S., Marchetti N., "IMT-Advanced : Technological Requirements and Solution Components" Proceeding of IEEE, Cognitive Radio and Advanced Spectrum Management,. CogART 2009, 2009

[9]. Lee J., Han J., Zhang J., "MIMO Technologies in 3GPP LTE and LTE-Advanced", Hindawi Publishing Corporation, EURASIP Journal on Wireless Communications and Networking, Vol 2009, Article ID 302092, 2009

[10]. David A. Hall, ED Online ID \# 21225, May, 2009, “ Understanding Benefits of MIMO Technology",

URL http://www.mwrf.com/Articles/Index.cfm?Ad=1\&ArticleID=21225\#

[11]. LI Qlnghua, Eddle Lin X., Zhang J., and Roh W., "Advancement of MIMO Technology in WiMAX : From IEEE $802.16 \mathrm{~d} / \mathrm{e} / \mathrm{j}$ to $802.16 \mathrm{~m}$

[12]. Clerckx B., Mazzarese D., Kim G., and Kim S. "Multiuser MIMO Downlink Made Practical : Application to IEEE $802.16 \mathrm{~m}$ "

[13]. Mourad A., Gutierrez I., Dec 2009, "System Level Evaluation for WiMAX IEEE 802.16m", Performance Computing and Communications Conference (IPCCC), 2009 IEEE 28th International conference, , pp 418-424

[14]. Ahmadi Sussan, 2011 Edition, "Mobile WiMAX Approach: A System Approach to Understanding IEEE 802.16m Radio Access technology".

\section{Authors}

Amit Chaturvedi has obtained his Masters degree in Computer Applications (MCA) from M.P. Bhoj(o) Univ, Bhopal and doing Ph.D. from Bhagwant University, Ajmer. He is having 5 years of research experience in Wireless Communication. He is having good number of research papers in this area.

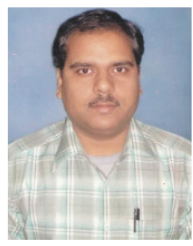


Prof. A.K. Solanki, Director, MIET, Meerut, [U.P], India, has obtained his Ph.D. in Computer Science \& Engineering from Bundelkhand University, Jhansi. He has more than 24 years of teaching experience. Prof. Solanki is also appointed as an executive committee member of National Executive Council of Indian Society of Technical Education (ISTE) for three years 2009-2012 for Uttar Pradesh and Uttrakhand region. He is a member of BOS/RDC in many universities and also the member of selection \& inspection committee of AICTE, GBTU and other universities. He has published a good number of International \& National Research papers in the area of Data warehousing, web mining and Wireless Communications and always ready to teach the subjects to his students which he does with great finesse. 